ORIGINAL ARTICLE

\title{
Influence of an injury reduction program on injury and fitness outcomes among soldiers
}

\author{
J J Knapik, S H Bullock, S Canada, E Toney, J D Wells, E Hoedebecke, B H Jones
}

Injury Prevention 2004;10:37-42. doi: 10.1136/ip.2003.002808

See end of article for authors' affiliations

.....................

Correspondence to: Dr Joseph Knapik, Directorate of

Epidemiology and Disease

Surveillance, US Army

Center for Health

Promotion and Preventive

Medicine, Aberdeen

Proving Ground, MD

21010, USA; joseph

knapik@apg.amedd. army.mil

\begin{abstract}
Objective: This study evaluated the influence of a multiple injury control intervention on injury and physical fitness outcomes among soldiers attending United States Army Ordnance School Advanced Individual Training.

Methods: The study design was quasiexperimental involving a historical control group $(n=2559)$ that was compared to a multiple intervention group $(n=1283)$. Interventions in the multiple intervention group included modified physical training, injury education, and a unit based injury surveillance system (UBISS). The management responsible for training independently formed an Injury Control Advisory Committee that examined surveillance reports from the UBISS and recommended changes to training. On arrival at school, individual soldiers completed a demographics and lifestyle questionnaire and took an army physical fitness test (APFT: push-ups, sit-ups, and two mile run). Injuries among soldiers were tracked by a clinic based injury surveillance system that was separate from the UBISS. Soldiers completed a final APFT eight weeks after arrival at school.

Results: Cox regression (survival analysis) was used to examine differences in time to the first injury while controlling for group differences in demographics, lifestyle characteristics, and physical fitness. The adjusted relative risk of a time loss injury was 1.5 (95\% confidence interval 1.2 to 1.8$)$ times higher in the historical control men and 1.8 (95\% confidence interval 1.1 to 2.8 ) times higher in the historical control women compared with the multiple intervention men and women, respectively. After correcting for the lower initial fitness of the multiple intervention group, there were no significant differences between the multiple intervention and historical control groups in terms of improvements in push-ups, sit-ups, or two mile run performance.
\end{abstract}

Conclusions: This multiple intervention program contributed to a reduction in injuries while improvements in physical fitness were similar to a traditional physical training program previously used at the school. a njuries have gained attention in the United States military as the magnitude of the injury problem has become apparent. About half of all deaths, half of all disabilities, and half of all outpatient medical visits appear to be due to injuries. Injuries result in five to 22 times more days of limited duty than do illnesses. ${ }^{12}$ Risk factors for training injuries in various military populations have been identified $^{134}$ and specific interventions have been tested that successfully reduce injuries without compromising mission effectiveness..$^{5-9}$ These studies demonstrate that injuries are not an inevitable consequence of military training and operations and can be successfully controlled.

Since 1999, the United States Army Center for Health Promotion and Preventive Medicine has worked with Kirk Army Health Clinic and the United States Army Ordnance Center and School at Aberdeen Proving Ground, Maryland, to maintain an injury surveillance system. This system captures the visits of advanced individual training (AIT) students to the medical clinics at Aberdeen Proving Ground. Weekly surveillance reports are supplied to commanders of the AIT units and these reports show the proportion of injured soldiers. The surveillance system also collected activities associated with injury and demonstrated that a large proportion of injuries were associated with physical training. Because of this, physical training was targeted for injury reduction efforts. Other interventions were also instituted including education on injury reduction techniques and introduction of a unit based surveillance system. This paper reports on injury and fitness outcomes from this multiple intervention program.

\section{METHODS}

Participants and study design

Participants were soldiers attending ordnance AIT at Aberdeen Proving Ground, Maryland, USA. Soldiers trained to qualify for one of five different military occupational specialties, all of which involve vehicle repair and maintenance. Two cohorts were compared. The historical control was comprised of soldiers attending AIT before the interventions were introduced. The multiple intervention cohort was comprised of soldiers attending AIT after the interventions were introduced.

\section{Interventions}

Physical training program

The traditional physical training program of the historical control cohort involved primarily warm-up and stretching exercises followed by calisthenics, variations on push-up and sit-up exercises, group long distance running, and some interval training (sprints). ${ }^{10}$ The multiple intervention group performed the new physical readiness training (PRT) program for which the theoretical rationale and exercise details have been described previously. ${ }^{911}{ }^{12}$ Injury reduction measures incorporated into the program included reduced

\footnotetext{
Abbreviations: AIT, advanced individual training; ANCOVA, analysis of covariance; ANOVA, analysis of variance; APFT, army physical fitness test; PRT, physical readiness training; RPT, remedial physical training; UBISS, unit based injury surveillance system
} 
running mileage, progressive overload, more individualized aerobic training, and cross training. ${ }^{4}{ }^{11} 13-16$

Personnel from the United States Army Physical Fitness School developed the PRT program and provided drill sergeants with a 32 hour block of field instruction on the exercises. Drill sergeants subsequently administered the program to the soldiers. PRT included calisthenics, movement (guerrilla) drills, dumbbell exercises, climbing drills, recovery drills, interval training, and ability group long distance running. ${ }^{11}$ Exercises were administered in a progressive manner by increasing the number of repetitions over days. Different exercises were performed on alternating days. Interval training was performed 1-2 times each week and involved six to 10 repetitions of 30 second sprints alternating with 90 second walks. Ability group long distance runs were performed about once a week and involved distances of no more than two miles. Ability groups were four aggregates of soldiers with similar speed who ran together. Training for both the historical control and multiple intervention cohorts was conducted five days/week for about one hour.

\section{Injury control education course}

A second intervention involved seven hours of classroom instruction on injury awareness and injury control techniques provided to the unit staff and student trainers. Previous studies have shown that combing aspects of educational efforts with community leadership participation, modification of attitudes, behaviors and norms, and alterations in the physical environment can be effective in reducing injuries. ${ }^{17-21}$ The injury control education course covered physiological principles, physical training concepts, injury prevention research and techniques, application of risk management techniques, and practical exercises.

\section{Unit based injury surveillance system}

The unit based injury surveillance system (UBISS) was a Microsoft Access relational database that allowed training personnel to enter individual soldier injury data from a routine form completed by medical personnel. Data entered into the surveillance system included name, type of injury, body part, activity associated with injury, and type and length of activity restriction. Eighteen real time graphs and charts could be generated.

\section{Data collected}

Lifestyle characteristics and demographics

Soldiers completed a Soldier Health Inprocessing Questionnaire on arrival at Aberdeen Proving Ground. Questions included date of birth, gender, race, basic combat training site, whether or not the soldier currently had an injury or illness that might affect their AIT performance, and tobacco use history. The Ordnance School provided data on each soldier's military occupational specialty, component (active Army, reserve, national guard), date of arrival, and date of departure from Aberdeen Proving Ground.

\section{Clinic based injury surveillance system}

When a soldier reported to the medical clinic for an injury the medical care provider filled out a form that contained questions on the activity associated with the injury, anatomic location of the injury, diagnosis, and days of limited duty. This form was scanned into the clinic based injury surveillance system. An injury was defined as physical damage to the body for which the soldier sought medical care and for which there was some restriction of duty for a day or more. Injury types were determined by diagnosis. Time loss overuse injuries included stress fractures, stress reactions, tendinitis, bursitis, fasciitis, arthritis, neuropathy, radiculopathy, shin splints, synovitis, strains, and musculoskeletal pain (not otherwise specified). Time loss traumatic injuries included sprains, dislocations, fractures, blisters, abrasions, lacerations, contusions, subluxations, and pain (due to a traumatic event). A third type of injury was any time loss injury, which included diagnoses from both the overuse and traumatic types.

\section{Army physical fitness test}

The army physical fitness test (APFT) involved the number of push-ups and sit-ups successfully completed in separate two minute periods and a two mile run for time. Initial APFTs were given within the first week of arrival at AIT, diagnostic tests were performed in the fourth week, and the first final test was performed in the eighth week. Soldiers had to meet age and gender adjusted standards to "pass" the APFT. ${ }^{10}$ Soldiers who did not pass the first final test were given additional APFTs and there were no limits on the number of additional tests. Soldiers who could not pass the APFT after the additional tests were discharged from military service.

\section{Training observations}

In the historical control group, physical training was observed for a three week period before the interventions. Training was observed in the multiple intervention cohort during the entire study period and trainers were required to conform to the training schedule.

\section{Remedial physical training (RPT)}

The training unit instituted a remedial physical training (RPT) program on week 16 of the 36 week multiple intervention period. RPT involved a second one hour physical training session on Mondays, Wednesdays, and Fridays. The reason for RPT was an anecdotal perception by trainers that more soldiers were failing the APFT than had failed in previous times. Soldiers who failed the diagnostic APFT or the first final APFT were assigned to RPT. Soldiers remained there until they passed the APFT or until they were discharged. Activities in RPT involved push-up/sit-up improvement exercises, cardiorespiratory training, and nautilus circuit training. The historical control group also had a remedial training program after which the multiple intervention RPT program was modeled.

\section{Injury Control Advisory Committee}

Presumably as a result of the educational program, unit training personnel independently developed an Injury Control Advisory Committee. This was a structured monthly forum in which the unit trainers and management evaluated their unit's current injury status from UBISS and discussed actions to reduce injuries. This group met seven times during the course of the study for about one hour each time. Meetings were attended by a physical therapist.

\section{Data analysis}

The Statistical Package for the Social Sciences, version 10.1.0, was used for all analyses. The Pearson $\chi^{2}$ test of proportions was used to examine historical control and multiple intervention group differences involving counts of people (that is, demographics, lifestyle characteristics, APFT pass rates). A one way analysis of variance (ANOVA) was used to examine group differences in age and initial APFT scores.

Cox regression (a survival analysis technique) was used to examine differences between the multiple intervention and historical control groups in crude and adjusted (covariates controlled) injury risk with separate analyses conducted for each of the three injury types. Continuous APFT variables converted into gender specific quartiles and age was divided into four groups. Simple contrasts were used to compare the crude and adjusted injury risk in historical control and 
multiple intervention groups. The multiple intervention group was the reference group with a risk ratio of 1.0.

APFT scores were analyzed using ANOVA (group by initial/ first final test). If initial APFT scores differed, analysis of covariance (ANCOVA) was used: the initial APFT score as the covariate and group comparisons were made on the final score.

\section{RESULTS}

There were 1122 men and 161 women in the multiple intervention cohort and 2303 men and 256 women in the historical control cohort. Soldiers who overlapped both periods (352 men and 40 women) were not included in the analyses.

\section{Demographics, lifestyle characteristics, and initial fitness}

Table 1 shows comparative demographic and lifestyle characteristics. Table 2 shows comparative age and fitness. Among the men, there were differences between the multiple intervention and historical control groups by rank, occupational specialty, race, basic combat training location, soldiers reporting injury on arrival, age, push-ups, and sit-ups. Among the women, the multiple intervention and historical control groups differed on occupational specialty, basic combat training location, and push-ups.

\section{Injury outcomes}

Table 3 shows the person-time injury incidence rates. In all cases, rates are higher for the historical control group than for the multiple intervention group. Table 4 displays the results of the Cox regression showing the crude and adjusted risk of injury in the historical control group relative to the multiple intervention group. The crude risk of injury is higher in the historical control group than in the multiple intervention group, although the 0.05 confidence interval was reached only for overuse injury in men and women and traumatic injury in the men. After adjustment for covariates, injury risk in the historical control group was higher than in the multiple intervention group for all injury types except for traumatic injuries among the women.

\section{Fitness outcomes}

Table 5 shows the proportion of soldiers that passed the APFT. More historical control men passed the initial test compared with multiple intervention men. The multiple intervention and historical control men did not differ on the proportion passing the first final test or passing after all tests had been completed. For the women, there were no group differences on the initial test, first final test, or after all final tests were completed.

Table 6 shows the APFT scores. Since there were significant group differences on the initial test of push-ups and sit-ups

\begin{tabular}{|c|c|c|c|c|c|c|}
\hline \multirow[b]{2}{*}{ Variable } & \multicolumn{3}{|l|}{ Men } & \multicolumn{3}{|l|}{ Women } \\
\hline & MI (\%) & $\mathrm{HC}(\%)$ & p Value* & MI (\%) & $\mathrm{HC}(\%)$ & p Value* \\
\hline \multicolumn{7}{|l|}{ Rank } \\
\hline Private One & 64.7 & 60.4 & \multirow{4}{*}{0.02} & 58.4 & 52.0 & \multirow{4}{*}{0.59} \\
\hline Private Two & 19.5 & 22.8 & & 21.7 & 25.8 & \\
\hline Private First Class & 13.1 & 13.1 & & 15.5 & 18.4 & \\
\hline Specialist & 2.4 & 3.8 & & 4.3 & 3.9 & \\
\hline \multicolumn{7}{|c|}{ Military occupational specialty $\ddagger \ddagger$} \\
\hline $63 G$ & 8.5 & 8.6 & \multirow{5}{*}{$<0.01$} & 6.8 & 5.1 & \multirow{5}{*}{$<0.01$} \\
\hline $63 \mathrm{~W}$ & 59.4 & 61.7 & & 68.3 & 83.2 & \\
\hline 63D & 5.3 & 9.6 & & 0.0 & 0.0 & \\
\hline $63 \mathrm{H}$ & 12.7 & 10.2 & & 14.3 & 9.8 & \\
\hline $63 Y$ & 14.1 & 9.9 & & 10.6 & 2.0 & \\
\hline \multicolumn{7}{|l|}{ Race } \\
\hline Black & 11.5 & 16.3 & \multirow{4}{*}{$<0.01$} & 21.5 & 20.6 & \multirow{4}{*}{0.56} \\
\hline Caucasian & 63.8 & 61.3 & & 58.4 & 61.0 & \\
\hline Hispanic & 14.8 & 14.2 & & 8.7 & 9.6 & \\
\hline Other & 9.9 & 8.2 & & 8.7 & 11.4 & \\
\hline \multicolumn{7}{|l|}{ BCT Location†£ } \\
\hline Fort Jackson, SC & 24.2 & 10.7 & \multirow{6}{*}{$<0.01$} & 81.9 & 64.1 & \multirow{6}{*}{$<0.01$} \\
\hline Fort Knox, KY & 56.8 & 67.4 & & 0.7 & 0.5 & \\
\hline Fort Leonard Wood, MO & 6.0 & 4.3 & & 12.8 & 18.6 & \\
\hline Fort Benning, GA & 7.8 & 11.3 & & 0.0 & 0.0 & \\
\hline Fort Sill, OK & 4.0 & 4.2 & & 4.0 & 15.5 & \\
\hline Other & 1.2 & 2.1 & & 0.7 & 1.4 & \\
\hline \multicolumn{7}{|l|}{ Injury on entry } \\
\hline Yes & 7.4 & 9.7 & \multirow{2}{*}{0.04} & 19.6 & 16.9 & \multirow{2}{*}{0.51} \\
\hline \multirow{2}{*}{\multicolumn{7}{|c|}{ Illness on entry }} \\
\hline & & & & & & \\
\hline Yes & 2.0 & 2.9 & \multirow[t]{2}{*}{0.14} & 4.1 & 2.7 & \multirow[b]{2}{*}{0.48} \\
\hline No & 98.0 & 97.1 & & 95.9 & 97.3 & \\
\hline \multicolumn{7}{|l|}{$\begin{array}{l}\text { Cigarette smoking (once in } \\
30 \text { days before BCT§) }\end{array}$} \\
\hline & 43.3 & 45.7 & \multirow[t]{2}{*}{0.23} & 40.9 & 41.4 & \multirow[b]{2}{*}{0.93} \\
\hline No & 56.7 & 54.3 & & 59.1 & 58.6 & \\
\hline \multicolumn{7}{|c|}{$\begin{array}{l}\text { Smokeless tobacco use (once in } \\
30 \text { days before } \mathrm{BCT} \S \text { ) }\end{array}$} \\
\hline Yes & 16.9 & 17.0 & \multirow[t]{2}{*}{0.92} & 5.4 & 3.6 & \multirow[b]{2}{*}{0.41} \\
\hline No & 83.1 & 83.0 & & 94.6 & 96.4 & \\
\hline
\end{tabular}

*From $\chi^{2}$ statistic.

tIn analysis of military occupational specialty and basic combat training location, zero cells were not included in the analysis.

$\ddagger$ Military occupational specialties: $63 \mathrm{G}$, fuel and electrical system repairer; $63 \mathrm{~W}$, wheel vehicle repairer; $63 \mathrm{D}$, self propelled field artillery system mechanic; $63 \mathrm{H}$, track vehicle repairer; $63 \mathrm{Y}$, track vehicle mechanic. $\S B C T$, basic combat training. 
Table 2 Age and fitness comparison of multiple intervention (MI) and historical control (HC) cohorts; values are mean (SD)

\begin{tabular}{|c|c|c|c|c|c|c|}
\hline \multirow[b]{2}{*}{ Variable } & \multicolumn{3}{|l|}{ Men } & \multicolumn{3}{|l|}{ Women } \\
\hline & MI & $\mathrm{HC}$ & p Value* & MI & $\mathrm{HC}$ & p Value* \\
\hline Age (years) & $19.8(2.8)$ & $20.4(3.3)$ & $<0.01$ & $20.1(3.3)$ & $20.4(3.2)$ & 0.48 \\
\hline Push-ups (reps) & $50.4(11.4)$ & $53.8(12.5)$ & $<0.01$ & $28.8(9.5)$ & $33.7(11.6)$ & $<0.01$ \\
\hline Sit-ups (reps) & $61.0(9.9)$ & $62.5(10.2)$ & $<0.01$ & $59.8(10.8)$ & 61.8 (11.9) & 0.22 \\
\hline Two mile run (min) & $14.9(1.4)$ & $14.9(1.4)$ & 0.69 & $18.4(2.3)$ & $18.3(2.0)$ & 0.88 \\
\hline
\end{tabular}

Table 3 Person-time injury incidence rates (injuries/100 person-months) for multiple intervention (MI) and historical control $(\mathrm{HC})$ cohorts

\begin{tabular}{llll}
\hline Group & $\begin{array}{l}\text { Any time loss } \\
\text { injury }\end{array}$ & $\begin{array}{l}\text { Time loss } \\
\text { overuse injury }\end{array}$ & $\begin{array}{l}\text { Time loss } \\
\text { traumatic injury }\end{array}$ \\
\hline $\mathrm{HC}$ & & 7.5 & 3.4 \\
Men & 10.3 & 13.4 & 4.6 \\
Women & 15.5 & 6.7 & 2.5 \\
Ml & & 9.7 & 3.3 \\
Men & 9.7 & & \\
Women & 14.0 & &
\end{tabular}

for men, ANCOVA was used to analyze these two events. After adjustment, there were no significant group differences on the first final test for push-ups $(p=0.74)$ or sit-ups $(p=0.41)$. A $2 \times 2$ ANOVA on the two mile run test demonstrated a significant main effect for test periods $(\mathrm{p}<0.01)$ but not for groups $(\mathrm{p}=0.90)$; the probability value for the interaction was $\mathrm{p}=0.07$.

Historical control and multiple intervention women demonstrated a significant difference on the initial test of push-ups. ANCOVA revealed no significant group differences on the first final test of push-ups $(p=0.20)$. A $2 \times 2$ ANOVA on sit-ups demonstrated a significant main effect for test periods $(p<0.01)$ but not for groups $(p=0.19)$ and the interaction was not significant $(p=0.71)$. On the two mile run, there was a significant difference for the test periods $(p<0.01)$ but not for groups $(p=0.70)$ and the interaction was not significant $(\mathrm{p}=0.68)$.

\section{DISCUSSION}

This study examined injury and fitness outcomes during implementation of a multiple intervention program. Soldiers who participated in the intervention program experienced lower injury rates than those who did not participate in the intervention program while improvements in APFT scores were similar. This multiple intervention program was successful in reducing injuries while improving physical fitness to the same extent as the control group.

\section{Educational program}

It has been shown that educational efforts alone have only very limited success in reducing injuries. ${ }^{22-27}$ On the other hand, "community based approaches" have shown more promise. ${ }^{17}$ Community based approaches combine aspects of educational efforts with focused community leadership participation, multiagency collaboration, tailoring to the needs of the local community, modification of attitudes, behaviors, and norms, and alterations in the physical environment. In this approach, public health personnel work within the community and consider perceived needs, use local knowledge and expertise, and encourage community ownership of the problem. ${ }^{18-21} 28-30$ The injury control program used in this project contained many of these elements.

\section{Physical training}

Concerns with the PRT program arose when the drill sergeants and training management noticed that seemingly larger than normal groups of soldiers began to fail the diagnostic and first final APFT. At the time, these failures were attributed to the PRT program and RPT was instituted to correct this. In retrospect, it can now be seen that multiple intervention soldiers were less fit on entry compared with their historical control counterparts (table 5). Despite this lower initial fitness, the first final APFT pass rate and ultimate APFT pass rate did not differ between the two groups (table 5). These data suggest that the PRT program (with remedial training) resulted in larger improvements in APFT pass rates than the traditional program (which also had a remedial program).

Certain features of the PRT training program have been shown to reduce injuries or are suspected of reducing injuries. These features may account for portions of the reduction in injury rates in this study. One of these features was lower running mileage. Observations on the historical control group suggested they ran an average of 7.1 miles/ week, while the multiple intervention group ran no more than 3.5 miles/week. Past studies with both military and civilian samples have strongly suggested that as the total amount of running decreases, the incidence of injuries decreases $^{4}$ 13 $^{14}$ 31-34 $^{-3}$ with little effect on improvements in aerobic fitness. ${ }^{4} 1314$

Table 4 Crude and adjusted risk ratios ( $95 \%$ confidence intervals) for the three types of injuries comparing multiple intervention (MI) and historical control $(\mathrm{HC})$ cohorts (risk ratios are $\mathrm{HC} / \mathrm{Ml}$ from Cox regression)

\begin{tabular}{llll}
\hline Analysis & Any time loss injury & Time loss overuse injury & Time loss traumatic injury \\
\hline $\begin{array}{l}\text { Men } \\
\text { Crude }\end{array}$ & $1.13(0.98$ to 1.30$)$ & $1.18(1.00$ to 1.40$)$ & $1.38(1.06$ to 1.81$)$ \\
$\quad \begin{array}{l}\text { Adjusted } \\
\text { Women }\end{array}$ & $1.46(1.21$ to 1.77$)$ & $1.58(1.26$ to 1.99$)$ & $1.50(1.06$ to 2.12$)$ \\
Crude & $1.31(0.96$ to 1.79$)$ & $1.65(1.14$ to 2.38$)$ & $1.40(0.75$ to 2.62$)$ \\
Adjusted & $1.77(1.10$ to 2.83$)$ & $2.52(1.47$ to 4.31$)$ & $1.37(0.57$ to 3.29$)$ \\
\hline
\end{tabular}


Table 5 Comparison of proportion of multiple intervention (MI) and historical control (HC) cohorts passing the army physical fitness test (APFT)

\begin{tabular}{|c|c|c|c|c|c|c|}
\hline \multirow[b]{2}{*}{ Group } & \multicolumn{3}{|l|}{ Men } & \multicolumn{3}{|c|}{ Women } \\
\hline & $\begin{array}{l}\text { Initial } \\
\text { APFT }\end{array}$ & $\begin{array}{l}\text { First } \\
\text { final } \\
\text { APFT }\end{array}$ & $\begin{array}{l}\text { All final } \\
\text { APFTs }\end{array}$ & $\begin{array}{l}\text { Initial } \\
\text { APFT }\end{array}$ & $\begin{array}{l}\text { First } \\
\text { final } \\
\text { APFT }\end{array}$ & $\begin{array}{l}\text { All final } \\
\text { APFTs }\end{array}$ \\
\hline MI (\% passed) & 66.7 & 80.7 & 99.6 & 60.5 & 74.4 & 98.7 \\
\hline $\mathrm{HC}$ (\% passed) & 72.0 & 83.7 & 99.0 & 57.0 & 75.5 & 97.3 \\
\hline p Value* & $<0.01$ & 0.24 & 0.19 & 0.64 & 0.92 & 0.48 \\
\hline
\end{tabular}

${ }^{*}$ From $\chi^{2}$ statistic comparing multiple intervention and historical control groups.

Following the exercise principle of progressive overload, the intervention program emphasized the gradual introduction of the exercises. ${ }^{6}{ }^{15}$ This was another potential injury reduction feature. In the historical control group, newly arrived soldiers performed whatever physical training the unit had planned for that day without the gradual introduction of exercise stress. Soldiers in the multiple intervention program were provided a program that allowed them to learn and gradually adapt to the new PRT exercises.

Another factor possibly associated with the lower multiple intervention injury rates may have been the ability group runs. It was observed that during historical control runs, the entire training group would run together but some individuals, presumed to have lower fitness, would drop out of the run. Ability group runs performed by the multiple intervention group permitted less fit soldiers to run at speeds more appropriate to their lower aerobic capacities and may have avoided excessive fatigue that is associated with gait changes $^{35-38}$ and may be associated with injuries.

A final training related factor that may partially account for the lower injury rates in the multiple intervention group was the variety of exercises in the PRT program. There are no studies indicating that a greater variety of exercise will reduce injuries, but sports medicine professionals often recommend "cross training" (different exercises on different days) for this purpose. ${ }^{16}$

\section{Injury surveillance and Injury Control Advisory Committee}

The major purposes of injury surveillance are to assess health status, conduct research, determine public health priorities, and evaluate programs. ${ }^{39}$ The clinic based injury surveillance system was used to demonstrate the injury problem and show that physical training was the major activity associated with injuries. The system was then used to evaluate the effectiveness of the intervention programs.

The UBISS allowed unit personnel to print out a wide variety of charts and graphs which were used during the
Injury Control Advisory Committee meetings to report specific unit injury rates. Currently there are no studies indicating that such a committee can reduce the incidence of injuries. However, systematic examination of data and discussion of injury prevention priorities may be effective if the information gained from such sessions is applied and policies enforced. ${ }^{40}$ Direct observations of the Injury Control Advisory Committee suggested that the committee used most of the meeting time to share surveillance reports and less time discussing trends and solutions. It is unclear how injury rates could have been affected by this committee or the UBISS other than by raising awareness of injury rates and activities associated with injuries.

\section{Limitations}

This study used a historical control group which could have been influenced by temporal changes that were not apparent or were difficult to identify because they occurred in the past and were not monitored when they occurred. The three weeks of physical training observations on the historical control group may not have been representative of the physical training performed during the entire historical control period. A number of different medical care providers were in the clinic during the study period and may have had different criteria for assigning restricted duty. Remedial physical training was not originally planned for the multiple intervention group and was not instituted until the historical control portion of the study was about $40 \%$ complete. However, since the historical control group had a similar program this may have had the unintended effect of making the groups more similar.

The fact that multiple interventions were examined in this study made it difficult to determine which interventions were most effective in reducing injuries. The multiple strategies may have been successful because different individuals responded to different aspects of the program. The PRT program has the most injury reduction potential based on the literature cited above. It is not clear how the injury control education course, UBISS, or the Injury Control Advisory Committee influenced injury risk. Nevertheless, the evaluation showed the overall multiple intervention program succeeded. Future studies should involve prospective cohort designs and attempt to partition out the influence of each intervention separately.

\section{ACKNOWLEDGEMENTS}

We would like to thank COL John Hills, LTC Anthony Grant, ILT Kevin Heinonen, CPT Jeffrey Long, SFC Richard Kammerling, Mr Dee Dailidonis (SFC, ret), LTC William Rieger, Mr Frank Palkoska, MAJ Danny McMillian, Mr Steven VanCamp, SFC Dennis Edwards SFC Mathew Billet, LTC Bruno Petruccelli, MAJ Sonya Corum, SFC Jennifer Brown, MSG Mark Kenyon, Ms Lisa Young, Ms Rebecca Weese, Ms Carol Pace, Ms Lisa Young, Ms Andrea Norris, LTC Joan Lyon, COL Valerie Rice, LTC Annette Bergeron, Ms Melissa Bonds,

Table 6 Army physical fitness test (APFT) scores of the multiple intervention (MI) and historical control (HC) cohorts; values are mean (SD)

\begin{tabular}{lllll}
\hline Gender & Group & Push-ups (reps) & Sit-ups (reps) & Two mile run (min) \\
\hline $\begin{array}{llll}\text { Men } \\
\quad \text { Initial test }\end{array}$ & $\mathrm{Ml}$ & $50.4(11.4)$ & $61.0(9.9)$ & $14.9(1.4)$ \\
& $\mathrm{HC}$ & $53.8(12.5)$ & $62.5(10.2)$ & $14.9(1.4)$ \\
First final test & $\mathrm{Ml}$ & $53.5(11.3)$ & $64.8(9.9)$ & $14.7(1.4)$ \\
& $\mathrm{HC}$ & $56.3(12.6)$ & $65.8(10.3)$ & $14.6(1.3)$ \\
Women & & & & \\
$\quad$ Initial test & $\mathrm{Ml}$ & $28.8(9.5)$ & $59.8(10.8)$ & $18.4(2.3)$ \\
& $\mathrm{HC}$ & $33.7(11.6)$ & $61.8(11.9)$ & $18.3(2.0)$ \\
First final test & $\mathrm{Ml}$ & $32.1(9.4)$ & $64.2(9.4)$ & $17.9(1.5)$ \\
& $\mathrm{HC}$ & $37.3(12.6)$ & $66.4(12.0)$ & $17.8(2.0)$ \\
\hline
\end{tabular}

reps, repetitions 


\section{Key points}

- Ongoing surveillance at the United States Army Ordnance School documented the injury rate among students attending for advanced individual training and identified physical training as the major activity associated with injury.

- In an attempt to reduce injuries among the students a number of interventions were instituted. These included alterations in the physical training program, injury control education to the student trainers, a unit based surveillance system, and an Injury Control Advisory Committee.

- After the interventions were put in place there was a reduction in the overall injury rates with no change in the rate of improvement in physical fitness.

- The extent to which the individual interventions contributed to the total reduction in injuries could not be determined but the alterations in the physical training program was assumed to be the most effective based on the literature and since physical training was the predominate activity associated with injury.

- Future studies should examine each intervention individually so their relative effectiveness can be determined.

COL Mary Lopez, SFC Brian Testerman, SFC Dennis Bergeron, Dr Eric Lescault, COL Walter Egerton, and COL Kreeger.

\section{DISCLAIMERS}

The opinions or assertions contained herein are the views of the authors and are not to be construed as official or as reflecting the views of the Department of the US Army or the US Department of Defense.

Use of trademarked names does not imply endorsement by the US Army but is intended only to assist in identification of a specific product.

\section{Authors' affiliations}

J J Knapik, S H Bullock, S Canada, E Hoedebecke, B H Jones, United States Army Center for Health Promotion and Preventive Medicine, Aberdeen Proving Ground, Maryland

E Toney, M D Anderson Cancer Center, Houston, Texas

J D Wells, Brody School of Medicine, Department of Physical Medicine and Rehabilitation, East Carolina University, Greenville, North Carolina

\section{REFERENCES}

1 Jones BH, Knapik JJ. Physical training and exercise-related injuries. Surveillance, research and injury prevention in military populations. Sports Med 1999;27:111-25.

2 Knapik JJ, Jones BH, Hauret KG. Injury control in the United States military Australian Military Medicine Association Journal 2003 (in press).

3 Knapik JJ, Sharp MA, Canham-Chervak M, et al. Risk factors for trainingrelated injuries among men and women in basic combat training. Med Sci Sports Exerc 2001;33:946-54.

4 Jones BH, Cowan DN, Knapik JJ. Exercise, training and injuries. Sports Med 1994:18:202-14.

5 Knapik JJ, Reynolds K, Barson J. Influence of an antiperspirant on foot blister incidence during cross country hiking. J Am Acad Dermatol 1998;39:202-6.

6 Rice VJB, Connolly V, Bergeron A, et al. Evaluation of a progressive unitbased running program during advanced individual training. Ft Sam Houston, TX: US Army Medical Department Center and School. Project Aegis Technical Report NoT02-1, 2002.
7 Amoroso PJ, Ryan JB, Bickley B, et al. Braced for impact: reducing paratrooper's ankle sprains using outside-the-boot braces. J Trauma 1998;45:575-80

8 Knapik JJ, Hamlet MP, Thompson KJ, et al. Influence of boot sock systems on frequency and severity of foot blisters. Mil Med 1996;161:594-8.

9 Knapik JJ, Hauret KG, Arnold S, et al. Injury and fitness outcomes during implementation of physical readiness training. Int J Sports Med 2003;24:372-81.

10 Department of the Army. Physical fitness training. US Army field manual (FM) 21-20. Washington, DC: Headquarters, Department of the Army, 1992.

11 Knapik JJ, Hauret K, Bednarek JM, et al. The Victory fitness program. Influence of the US Army's emerging physical fitness doctrine on fitness and injuries in Basic Combat Training. Aberdeen Proving Ground, MD: US Army Center for Health Promotion and Preventive Medicine. Epidemiological Consultation Report No 12-MA-5762-01, 2001.

12 Department of the Army. Physical readiness training. Army field manual 325.20 (draft). Washington DC: Headquarters, Department of the Army, 2001.

13 Shaffer RA. Musculoskeletal injury project. Presented at the 43rd Annual Meeting of the American College of Sports Medicine. Cincinnati, OH, 1996.

14 Trank TV, Ryman DH, Minagawa RY, et al. Running mileage, movement mileage, and fitness in male US Navy recruits. Med Sci Sports Exerc 2001;33:1033-8.

15 McArdle WD, Katch FI, Katch VL. Exercise physiology: energy, nutrition and human performance. Philadelphia: Lea \& Febiger, 1991

16 Stamford B. Cross-training: giving yourself a whole-body workout. Physician Sportsmed 1996;24(9):15-16.

17 Klassen TP, MacKay JM, Moher D, et al. Community-based injury prevention interventions. Future Child 2000;10:83-110.

18 Timpka T, Lindqvist K, Schelp L, et al. Community-based injury prevention: effects on health care utilization. Int J Epidemiol 1999;28:502-8.

19 Robertson LS. Community injury control programs of the Indian Health Service: an early assessment. Public Health Rep 1986;101:632-7.

20 Knapik JJ, McCollam R, Canham-Chervak M, et al. Injuries and injury prevention among senior military officers at the Army War College. Mil Med 2002; 167:593-9.

21 Day LM, Ozanne-Smith J, Cassell E, et al. Evaluation of the Latrobe Valley Better Health Injury Prevention Program. Inj Prev 2001;7:66-9.

22 Hazard RG, Reid S, Haugh LD, et al. A controlled trial of an educationa pamphlet to prevent disability after occupational low back injury. Spine 2000;25:1419-23.

23 Daltroy LH, Iversen MD, Larson MG, et al. A controlled trial of an educational program to prevent low back injury. N Engl J Med 1997;337:322-8.

24 Dershewitz RA, Willamson JW. Prevention of childhood household injuries: a controlled clinical trial. Am J Public Health 1977;67:1148-53.

25 Preusser DF, Ulmer RG, Adams JR. Driver record evaluation of a drinking driver rehabilitation program. J Safety Res 1976;8:98-105.

26 Stevens $M$, Holman CD, Bennett N, et al. Preventing falls in older people: outcome evaluation of a randomized controlled trial. J Am Geriatr Soc 2001;49:1448-55.

27 Duperrex O, Roberts I, Bunn F. Safety education of pedestrians for injury prevention. Cochrane Database of Systematic Reviews 2002;CD001531.

28 Tinetti ME, Baker DI, McAvay G, et al. A multifactorial intervention to reduce the risk of falling among elderly people living in the community. N Engl J Med 1994:331:821-7.

29 Davidson LL, Durkin MS, Kuhn L, et al. The impact of the Safe Kids/Healthy Neighborhoods Injury Prevention Program in Harlem, 1988 through 1991. Am J Public Health 1994;84:580-6.

30 Towner E, Dowswell T. Community-based childhood injury prevention interventions: what works? Health Promotion International 2002;17:273-84.

31 Koplan JP, Powell KE, Sikes RK, et al. An epidemiologic study of the benefits and risks of running. JAMA 1982;248:3118-21.

32 Marti B, Vader JP, Minder CE, et al. On the epidemiology of running injuries. The 1984 Bern Grand-Prix study. Am J Sports Med 1988;16:285-94.

33 Powell KE, Kohl HW, Capersen CJ, et al. An epidemiological perspective on the causes of running injuries. Physician Sportsmed 1986;14(6):100-14.

34 Koplan JP, Rothenberg RB, Jones EL. The natural history of exercise: a 10-yr follow-up of a cohort of runners. Med Sci Sports Exerc 1995;27:1 180-4.

35 Nyland JA, Shapiro R, Stine RL, et al. Relationship of fatigued run and rapid stop to ground reaction forces, lower extremity kinematics, and muscle activation. J Orthop Sports Phys Ther 1994;20:132-7.

36 Candau R, Belli A, Millet GY, et al. Energy cost and running mechanics during a treadmill run to voluntary exhaustion in humans. Eur J Appl Physiol 1998:77:479-85.

37 Elliot B, Ackland T. Biomechanical effects of fatigue on 10,000 meter racing technique. Res Q Exerc Sport 1981;52:160-6.

38 Mair SD, Seaber AV, Glisson RR, et al. The role of fatigue in susceptibility to acute muscle strain injury. Am J Sports Med 1996;24:137-43.

39 Thacker SB. Principles and practices of public health surveillance. In Teutsch SM, Churchill RE, eds. New York: Oxford University Press, 1994.

40 Rice VJB, Pekarek D, Connolly V, et al. Participatory ergonomics: determining injury control "buy-in" of US Army cadre. Work 2002;18:191-203. 